\title{
O ORÁCULO DA NOITE: AUTOCONHECIMENTO E CONSTRUÇÃO DO FUTURO
}

\author{
EL ORÁCULO DE LA NOCHE: AUTOCONOCIMIENTO Y CONSTRUCCIÓN DE \\ FUTURO
}

\author{
THE ORACLE OF THE NIGHT: SELF-KNOWLEDGE AND CONSTRUCTION OF \\ THE FUTURE
}

Rita BRAGA ${ }^{1}$

RESUMO: Esta resenha pretende apresentar o livro de Sidarta Ribeiro, "O oráculo da noite: a história e a ciência do sonho", como uma leitura pertinente para a formação de professores, por abordar tópicos relevantes para o desenvolvimento integral e para formação cidadã. A obra traz contribuições tanto por meio do denso conteúdo científico que propõe registrar quanto por sua estrutura estilística e editorial. O relato sobre os desafios para comprovação de teorias freudianas - conectado a tantos outros - revela-se como um exemplo acessível acerca do rigor e da complexidade dos processos científicos, que enfrentam hoje ondas de negacionismo generalizado. O texto guarda ainda outras qualidades, sobretudo, pelo modo ético como conduz as análises, com distinções entre fatos e hipóteses, confrontando respeitosamente, várias perspectivas históricas, sociais e culturais.

PALAVRAS-CHAVE: Ciência. Cérebro. Autoconhecimento. Psicologia. Neurociência.

RESUMEN: Esta reseña pretende presentar el libro de Sidarta Ribeiro, "El oráculo de la noche: la historia y la ciencia del sueño", como una lectura pertinente para la formación de profesores, ya que aborda temas relevantes para el desarrollo integral y la formación ciudadana. La obra aporta contribuciones tanto por el denso contenido científico que se propone registrar como por su estructura estilistica y editorial. El informe sobre los desafios para probar las teorías freudianas -conectadas con muchas otras-se revela como un ejemplo accesible sobre el rigor y la complejidad de los procesos cientificos, que hoy se enfrentan a oleadas de negacionismo generalizado. El texto tiene también otras cualidades, especialmente por la forma ética en que realiza el análisis, con distinciones entre hechos e hipótesis, confrontando respetuosamente diversas perspectivas históricas, sociales y culturales.

PALABRAS CLAVE: La ciencia. Cerebro. Autoconocimiento. Psicología. Neurociencia.

ABSTRACT: This review intends to present the book "The Oracle of the Night: The History and Science of Dreams" by Sidarta Ribeiro, as a pertinent reading for teacher education, as it approaches relevant topics for integral development and citizen education. The work contributes both through the dense scientific content that it proposes to record and through its

${ }^{1}$ Secretaria Municipal de Educação de São Paulo (SMESP), São Paulo - SP - Brasil. Professora no Ensino Fundamental e Ensino Médio. Mestrado em Educação (USP). ORCID: https://orcid.org/0000-0002-5446-7437. Email: ritaeducativo@gmail.com 
stylistic and editorial structure. The story about the challenges to prove Freudian theories connected to so many others - reveals itself as an accessible example about the rigor and complexity of scientific processes, which today face waves of generalized negationism. The text also has other qualities, above all, for the ethical way in which it conducts its analyses, with distinctions between facts and hypotheses, respectfully confronting various historical, social, and cultural perspectives.

KEYWORDS: Science. Brain. Self-knowledge. Psychology. Neuroscience.

O neurocientista Sidarta Ribeiro, fundador e vice-diretor do Instituto do Cérebro da Universidade Federal do Rio Grande do Norte (UFRN), consolidou uma trajetória acadêmica internacional marcada por parcerias renomadas e com avanços científicos reconhecidos em todo o mundo. Em sua obra mais recente, $O$ oráculo da noite: a história e a ciência do sonho (RIBEIRO, 2019), este percurso é narrado em/por desafios, peripécias e descobertas. No tom adotado no livro, vê-se como a humanização da profissão no imaginário do leitor favorece o engajamento e a escuta do que está sendo enunciado. Esta experiência de leitura desperta possibilidades de abordagens da ciência na educação, sobretudo em tempos de negacionismo, desinformação e apatia.

O volume é um tratado rigoroso e sensível sobre um tema cujo estudo tem enfrentado muitos preconceitos: o papel do sonho na vida do ser humano. Antes de tudo, é um convite à introspecção e ao cultivo consciencioso do hábito de sonhar e narrar. Um processo que se desdobra na análise mais atenta da realidade e na postura ativa na construção do futuro.

Com generosidade, são apresentados experimentos e correlações entre cientistas, figuras históricas, animais e até personagens literárias - que em algumas passagens ajudam na visualização de conceitos.

Entre os objetivos centrais do livro está a busca de compreensão dos mecanismos fundamentais do sonho e de como ele "prepara o sonhador para o dia seguinte". Para isso, a narrativa reconstrói as etapas de avanço do espaço simbólico do sonho dentro de várias culturas e de como os cientistas alcançaram a façanha de testar teorias (freudianas e outras) que enfrentavam resistência no meio acadêmico. Note-se que organizar esses elementos num texto extenso e coerente é um processo tão desafiador quanto a própria pesquisa, por isso, Ribeiro (2019, p. 36), faz uma advertência que sintetiza a beleza do processo científico: "será necessário combinar a provisória suspensão da descrença com o compromisso de duvidar no fim”. Ressalta que "é crucial não tentar entender antes da hora, mas sim deixar-se levar pela correnteza até poder ver em perspectiva o conjunto da evidência levantada, necessariamente incompleta, mas ainda assim elucidadora". De fato, é o que ele oferece. 
São dezoito capítulos densos, mas com linguagem acessível ao leitor leigo, e um índice remissivo de quase trinta páginas - muito útil para resgatar detalhes e conexões que se tornam mais interessantes a cada parágrafo. $\mathrm{O}$ autor contextualiza de maneira minuciosa registros históricos, descobertas sobre os processos bioquímicos do sono e do sonho, explicando, inclusive, como evoluções tecnológicas interferem nas transformações do sonhar, nos comportamentos cotidianos e na capacidade científica de analisá-las.

O texto vai além de expor as razões, porque o sonho foi considerado divinatório em tantas culturas e civilizações. As reflexões perpassam, por exemplo, a manipulação de relatos oníricos para usos políticos e o modo como a (re)apropriação ética desse arcabouço simbólico pode ser frutífera para a construção de uma sociedade mais saudável. Essas são demandas caras à educação e a outras áreas do conhecimento, ainda mais numa época em que o excesso de estímulos turva a capacidade de distinguir fatos e discursos sobrepostos (e manipulados à exaustão).

Segundo o autor, há no sonho uma ponderação inconsciente sobre as possibilidades do futuro, com base nas experiências e impressões do passado. "Os sonhos não revelam o destino do sonhador amanhã, mas apenas seu rumo hoje" (RIBEIRO, 2019, p. 300). Algumas de suas colocações sobre essa funcionalidade despontam como aforismos, analogias e metáforas com significativo teor filosófico:

O sonho exprime o destino, mas não garante a chegada, como alguém que viaja com rumo certo mas pode parar antes, acelerar ou seguir rotas alternativas. Destino é para onde estamos indo, mas não necessariamente para onde vamos. Os sonhos bem sonhados vislumbram nosso destino através de simulações dos possíveis trajetos e desfechos. Sonhar é como tatear o quarto escuro com uma nesga de luz, quando as paredes são o próprio futuro (RIBEIRO, 2019, p. 352).

Confrontando perspectivas culturais em diferentes épocas, o leitor é estimulado a sair do olhar condicionado e etnocentrista, tantas vezes reproduzido em bolhas sociais. Os registros arqueológicos sobre os primeiros enterros rituais, por exemplo, permitem hipóteses sobre como o sonho com um ente próximo falecido pode ter causado alvoroço e ter iniciado esse campo divinatório, como uma posição de escuta e respeito. O que despertaria esse tipo de alvoroço respeitoso hoje? Se as lentas mudanças que levaram o ser humano do nomadismo ao sedentarismo, em milênios, trouxeram novidades simbólicas importantes, a avalanche de transformações das últimas décadas também movimentou mais do que economias mundiais. Partindo de considerações sobre esses e outros registros, Ribeiro (2019), lembra que o fenômeno da introspecção (a capacidade de imaginar e ouvir a si mesmo, sem "ouvir aos 
deuses") é um fenômeno recente e que mentalidade humana mudou radicalmente nos últimos 3 mil anos. De fato, comentando os trabalhos realizados por vários pesquisadores sobre a Era Axial, ele localiza indícios dessa mudança de paradigma - por sinal, associada à invenção da escrita e ao avanço da literatura, que começa deslocar a fonte das ações, levando-a dos deuses para protagonistas com consciência de si. Isso é demonstrado pelo autor na comparação entre os heróis Aquiles e Ulisses (RIBEIRO, 2019, p. 68-70).

Também são comentadas situações com indícios de que o relato onírico era valorizado a ponto de ser manipulado politicamente, como na decisão do Imperador Constantino perante o cristianismo (RIBEIRO, 2019, p. 295).

Vê-se depois, que esse mesmo cristianismo passará a considerar o oráculo do sonho como indício de influências heréticas, levando à execução de Giordano Bruno em 1600. "O descrédito dos sonhos se aprofundou no século XVIII, com o racionalismo que está na origem tanto da ciência quanto do capitalismo" (RIBEIRO, 2019, p. 80-81).

O cientista alinhava essas perspectivas para que pudéssemos compreender os reducionismos e embates que se intensificaram até o século XX (RIBEIRO, 2019, p. 256).

As críticas à tradição freudiana, "ao insistir que os sonhos são tentativas de cumprir desejos", são lembradas, contextualizadas e refutadas com experimentos científicos.

Ribeiro (2019) comenta que os enredos oníricos se complexificaram, conforme a própria cultura foi se tornando mais complexa. Isso aconteceu, por exemplo, com o aumento do tempo livre e a multiplicação dos estímulos (cinema, TV, internet, entre outros) que geraram uma explosão combinatorial dos enredos:

Se a onça do Pantanal sonha mil modos diferentes de abater a capivara, ainda assim são todos sonhos de caça, muito semelhantes entre si. Conosco não. As múltiplas necessidades da espécie humana criaram condições para que os sonhos se tornassem coleções desordenadas de imagens, colchas de retalhos de quereres. O sonho típico de nosso tempo é um liquidificador de sentidos, um caleidoscópio de vontades, fragmentado pela multiplicidade de desejos de nossa era (RIBEIRO, 2019, p. 293).

Nas idas e vindas entre relatos e análises, muitos aspectos relacionados ao tema são abordados. Entre eles: a história das descobertas sobre o sonho e a fisiologia do sono; as relações entre sonho e religião; as relações entre sono, memória e aprendizagem; as experiências e processos terapêuticos (inclusive com uso de algumas substâncias e estímulos bioquímicos assistidos com o objetivo de tratar traumas, depressão e esquizofrenia) e outras nuances do elo entre imaginação e saúde. 
Por um lado, o agrupamento dessas informações detalhadas no livro, fornecem ao leitor a base para compreender as raízes de teorias freudianas e as raízes da resistência a essas teorias devido à impossibilidade de testá-las à época. Por outro lado, o livro também semeia novos questionamentos e reflete quão instigante esse campo de pesquisa se tornou com o avanço tecnológico. O texto de Ribeiro (2019) sustenta-se sobre os experimentos pioneiros que identificaram as principais fases do sono: chamadas "sono de ondas lentas" e "sono de movimento rápido dos olhos" (sono REM, de "rapid eye movement").

O sono de ondas lentas domina a primeira metade da noite e é marcado por pouca geração de atividade elétrica no interior do cérebro, reverberando memórias sem vividez. Nessa fase, os pensamentos normais coexistem com a ausência de imagens sensoriais. Em contraste, no sono REM, ocorre uma grande ativação cerebral, que reverbera memórias com muita intensidade. Segundo o autor, “essa reverberação é o próprio material de que são feitos os sonhos" (RIBEIRO, 2019, p. 33-34).

A consolidação das pesquisas sobre o sono REM propiciou o enfrentamento do debate ideológico e comprovou a distinção entre sono REM e sonho, identificando este último por meio índice de dopamina. Ou seja, o que Freud observou a partir da análise de seus pacientes foi comprovado: "sonho “é' desejo porque ambos são dopamina" (RIBEIRO, 2019, p. 261).

No caminho desta longa jornada científica, são comentados os tipos mais recorrentes de sonhos (traumáticos, políticos, confortáveis, desafiadores, sonhos de luto, entre outros), e como eles diferem, conforme idade e outras características. Nota-se, por exemplo, que entre 5 e 7 anos as crianças apresentam narrativas oníricas nas quais elas não são protagonistas. Há histórias com pessoas ou animais, sendo que os meninos relatam mais personagens masculinos desconhecidos do que as meninas (RIBEIRO, 2019, p. 112).

Somente após os 7 anos começam a aparecer as narrativas do "eu", e aos 9, há um significativo avanço na capacidade de lembrar detalhes sensoriais. Dos 11 aos 13 anos, o universo da família começa a ser extrapolado nas narrativas. Percebem-se a partir desta fase, mais elementos de caráter, repertório intelectual e habilidade social, além de um equilíbrio maior nas emoções sonhadas, com ocorrência equivalente de afetos positivos e negativos. A complexidade varia, conforme o desenvolvimento intelectual e emocional de cada pessoa e como "o cérebro que sonha é o mesmo que vive a vigília, quanto mais complexo o tecido mental, mais complexo o sonho" (RIBEIRO, 2019, p. 114). Nesse sentido, essas nuances podem revelar algo sobre o momento presente de cada sonhador (RIBEIRO, 2019, p. 104-118).

Os estudos trouxeram descobertas relevantes para várias áreas do conhecimento - com destaque para a educação, visto que a aprendizagem está ligada a otimização saudável da 
memória. Afinal, o sono REM e o sonho são os principais agentes na seleção e organização do que é sedimentado ou esquecido (RIBEIRO, 2019, p. 104-105).

Ao realizar medições e análises do sono para identificar a relevância de fatores como "erro" e "novidade", as pesquisas muitas vezes, trazem conclusões que, a princípio, poderiam ser vistas como contraintuitivas para um processo de aprendizagem, como os intervalos para "supersonecas" para o aprendizado ortográfico (RIBEIRO, 2019, p. 177-179). Num dos experimentos, o autor nos mostra ou o autor sublinha que "o sono parece impedir que o sistema se acomode numa solução subótima" (RIBEIRO, 2019, p. 243-244).

Outro aspecto de interesse para educação são os relatos das inúmeras etapas de pesquisa como processo complexo e rigoroso, pois levanta questões desafiadoras inerentes ao próprio fenômeno da linguagem, seja no âmbito da comunicação geral ou das linhas psicoterapêuticas (RIBEIRO, 2019, p. 312-335).

A obra de Sidarta Ribeiro (2019) traz à tona a necessidade de fortalecimento dos valores esperados em um Estado de Direito Democrático, sobretudo nesse tempo em que ondas de negacionismo em diferentes campos têm multiplicado os problemas do mundo. Afinal, "é preciso perguntar: equipados com tanta tecnologia, saberemos sobreviver a nós mesmos?" (RIBEIRO, 2019, p. 376). Essa mesma reflexão está implícita nas considerações sobre "o impulsionamento massivo e automático de memes falsos que contagiam as pessoas até elas acharem que as narrativas mentirosas foram tecidas por elas mesmas”. E ressalta:

[...] É natural que o macaco se machuque com os brinquedos novos que inventa. Macacos adolescentes lançam alarmes falsos o tempo todo e são ignorados. Falar com milhares de pessoas ao mesmo tempo é um poder incalculável que ainda não aprendemos a usar direito (RIBEIRO, 2019, p. 378$379)$.

Ao longo de todo o livro há uma argumentação sobre "o potencial benigno da tomada de consciência possibilitada no sonho, que se apresenta como uma oportunidade de prospecção do próprio inconsciente" (RIBEIRO, 2019, p. 331). Há indicações sobre como diversas culturas elaboraram técnicas para desenvolver esse processo, passando pelo que ficou conhecido como "sonho lúcido" (RIBEIRO, 2019, p. 364-365). É importante registrar que essa argumentação é equilibrada por advertências contra "o uso hedonista do sonho lúcido" (RIBEIRO, 2019, p. 374), bem como contra as interpretações unívocas, que não levam em conta "a mais franca multiplicidade de sentidos possível, derivados das tantas associações fonéticas e semânticas, inclusive polissemias intra e interlinguísticas" (RIBEIRO, 2019, p. 335). Isto posto, o convite 
a leitura de si é tentador. Repete-se a cada manhã, e cada um pode começar seu "sonhário" a qualquer momento.

O desafio real é permitir que a introspecção redimensione o olhar ou nossos olhares para nós mesmos e na relação com o outro. Como diz o autor, "o espaço mental não é infinito, apenas vastíssimo.” (RIBEIRO, 2019, p. 335).

\section{REFERÊNCIAS}

RIBEIRO, S. O oráculo da noite: a história e a ciência do sonho. São Paulo: Companhia das Letras, 2019. 459 p.

\section{Como referenciar esta resenha}

BRAGA, R. O oráculo da noite: autoconhecimento e construção do futuro. Doxa: Rev. Bras. Psico. e Educ., Araraquara, v. 22, n. 00, p. e021005, 2021. e-ISSN: 2594-8385. DOI: https://doi.org/10.30715/doxa.v22i00.14656

Submissão em: $21 / 01 / 2021$

Revisões requeridas em: 19/03/2021

Aceito em:05/04/2020

Publicado em: 20/04/2021 